\title{
Modeling and experimental investigation of process parameters in WEDM for surface roughness using regression model
}

\author{
A. Muniappan*, R. Senthilkumar, V. Jayakumar, S. Venkata Ravikumar and P. Sai Tarunkumar \\ Department of Mechanical Engineering, Saveetha School of Engineering, Saveetha Institute of Medical and Technical Sciences, \\ Chennai, Tamil Nadu, India.
}

\begin{abstract}
The present study focused on the multiple regression modeling and predicting the surface roughness of the Aluminum hybrid composite during the WEDM process. The hybrid MMC was manufactured by process named as stir casting utilizing particulates of Silicon carbide and graphite each in A16061 combination. The analyses were outlined with Taguchi L27 design matrix. Mathematical relationships between the surface roughness and WEDM cutting parameters (Pulse on time, Pulse off time, current, gap voltage, wire speed and wire tension) have been investigated. The results show that the multiple regression analysis is a successful method for developing a mathematical model to predict the surface roughness. The optimum value of process parameters for the predicted optimum value of surface roughness (1.285) is pulse on time 106 units (Level 1), pulse off time 60 units (Level 3), peak current 90 units (Level 2), gap set voltage 50 units (Level 3), wire speed3 units (Level 1) and wire tension 12 units (Level 3). The optimum results are adopted in validation study and the results based on WEDM process responses can be effectively improved.
\end{abstract}

Keywords. WEDM, Taguchi method regression model, stir casting, hybrid composite and surface roughness.

\section{Introduction}

Running with the progression of the mechanical era, the solicitations for composite materials having high hardness, quality, wear assurance, and disintegration security are growing [1]. Research had been done in MMC composites more than a significant extended period of time, by examiners on creation methodologies and material property estimations, and various sublime research happens have been gained [2-4]. Metal system composites discover applications in air space industry and auto applications in perspective of their light weight, high particular quality and uncommon wear safe. Electrical release machining is one of the nonconsistent machining outlines which have been completely used to pass on jumble shapes, bombs hopelessly and shapes [5]. It is additionally utilized for completing parts for air space and automobile industry [6]. The machining of PAMCs presents a vital test, since various help materials are essentially harder than the routinely utilized snappy steel (HSS) and carbide instruments [7-8]. Wire electrical machining is an essential nonconventional machining process. It can be utilized to machine the electrically conductive work materials paying little regard to their quality and hardness. In the midst of machining in WEDM, no power is associated on sample work piece in the midst of machining in WEDM in light of the way that there is no prompt contact among gadget and work. The most key execution measures in WEDM are material ejection rate, surface finish, kerf and wire wear rate. Metal Composites possess good properties over metals The present work aims at applying Taguchi method for optimization of cutting speed machined by WEDM process of $\mathrm{Al} / \mathrm{SiC} / \mathrm{Gr}$ hybrid composite.

\section{Literature survey}

The true motivation behind this writing survey is to give foundation data on the issues to be considered in this postulation and to mention the present investigation. The utilization of aluminum composite is unavoidable in aviation and vehicle ventures attributable to its properties of high quality to weight proportion, excellent erosion protection, simple machinability and ease (Singh et al)[9]. Be that as it may, issues related with aluminum and its compound material is poor high temperature execution and low wear protection. To overcome this issues, new designing materials have been created by fortifying hard support material on delicate aluminum grid is called aluminum metal grid composites (Pedersen and Ramulu)[10]. Shyam lal and Sudhir Kumar [11-13] fabricated $\mathrm{Al} 7075 / \mathrm{Al}_{2} \mathrm{O}_{3} / \mathrm{SiC}$ hybrid composite \& studied the effect of WEDM parameters SR and kef width using Taguchi-Grey relational analysis. It was confirmed from results that roughness increased due to Pulse on time and current, because of longer spark with high intensity, higher material melts per spark on the surface. Adeel Ikram and Nadeem ahamd mufti [14] experimented result of WEDM parameters on MRR for gadget steel D2. They take wire reinforce speed, beat on-time, beat off-time, dielectric weight, open voltage, servo voltage and wire weight as information parameter. Han et al.[15] pick the machining parameters (tallying discharge current, beat length, beat between time, administered beat time, most distant point effect,

*Corresponding author: inspire.munish@gmail.com 
dielectric and material) on surface brutality. They recommend that a short pulse term combined close to a high apex regard gives better surface obnoxiousness. Ugrasen et al. [16] used Taguchi method close to the extortion neural framework to refresh the precision, surface seriousness and MRR. They found that for the more than three responses, current is the most goliath factor Sudhakara and Prasanthi [17] investigated machining parameters for tool steel in WEDM. They found the range perfect setting of different parameters as pulse on time $=108-128 \mu \mathrm{sec}$, beat off time $=47-63$ $\mu$ sec, peak stream $=11-13$ Amperes, begin opening set voltage $=18-68$ Volts, wire strain $=2-8$ Grams and water weight $=8-14 \mathrm{Kg} / \mathrm{cm}^{2}$. Kanlayasiri and Jattakul[18] found the perfect machining condition for dimensional deviation and SR for K460 instrument steel by wire EDM machine. They thought about cutting pace, top current, and change evacuate as information variable and dimensional accuracy and roughness of surface. They found that both current and alter disengage is gigantic factor for estimation while peak current impacts the surface unpalatability. Yam BH et al.[19] streamline the strategy parameters for EDM for HastelloyC276 by using Gray Relational Analysis. GRA, for finding the perfect parameters influencing both MRR and Kerf are accepted to be TON $=110 \mu \mathrm{s}$, $\mathrm{TOFF}=60 \mu \mathrm{s}, \mathrm{IP}=12 \mathrm{~A}, \mathrm{SV}=10 \mathrm{~V}$, for higher MRR \& lower Kerf width.The present study focuses on the modeling and prediction techniques to determine direct effects of WEDM parameters (Pulse on time, Pulse off time, current, gap voltage, wire speed and wire tension) on the surface roughness which is important for cutting dies and complex shapes.

\section{Materials and method}

\subsection{Preparation of hybrid composite}

In this investigation, the half and half MMC has been created by blend throwing process. The crossover composite comprises of $10 \mathrm{wt} \% \mathrm{SiC}$ and $5 \mathrm{wt} \%$ Graphite particulates in metal lattice Al6061 compound. The Al combination of 6xxx arrangement is having the capacity to be used in aviation and car ventures in light of its high quality to-weight proportion and great protection from consumption. Composition of Al6061 composite is appeared in Table 1. Fortifications $\mathrm{SiC}$ and graphite in particulate frame are utilized to create the hybrid composite. The easiest and the most savvy technique for fluid state creation is stir casting [19]. Fig.1 demonstrates the stircast equipment utilized for manufacture of hybrid composite.

\subsection{Machining parameters and response}

Machining process parameters in WEDM, Pulse on time, Pulse off time, current, gap voltage, wire speed and wire tension were considered as input parameters. Responses Surface roughness (SR) was measured after machining for investigation. The scopes of these procedure parameters were chosen on the premise of the pilot tests.
The levels of different parameters and its assignments are exhibited in Table 1.

Table 1. Process parameters and their levels

\begin{tabular}{ccccc}
\hline Symbol & $\begin{array}{c}\text { Process } \\
\text { parameter }\end{array}$ & Level 1 & $\begin{array}{c}\text { Level } \\
\mathbf{2}\end{array}$ & $\begin{array}{c}\text { Level } \\
\mathbf{3}\end{array}$ \\
\hline A & Pulse on time & 108 & 117 & 126 \\
B & Pulse off time & 40 & 50 & 60 \\
C & Pulse current & 90 & 160 & 230 \\
D & Gap set Voltage & 10 & 30 & 50 \\
E & Wire drum speed & 3 & 4 & 5 \\
F & Wire tension & 4 & 8 & 12 \\
\hline
\end{tabular}

\subsection{Experimental design using Taguchi method}

Taguchi strategy is a proficient apparatus for the outline of a great assembling framework. It also effectively solves some complex problems in manufacturing (Roy 1990).It is a strategy in view of OA tests, which give much decreased change to the try different things with ideal setting of process control parameters. The six control parameters, that is, pulse on time (A), pulse off time (B), top current (C), Gap set voltage (D), wire drum speed (E) and wire tension(F) at three levels were chosen in this examination. The tests were finished by Table 2 . This table just speaks to specific level of the different elements of the procedure at which the examinations would be directed.

\subsection{Experimental set up}

Analyses were led on Electronica Sprint cut (ElectraElplus 40A Dlx) CNC wire electrical release machine to think about the surface roughness influenced by the machining parameters at various levels. WEDM is a start disintegration process. The flashes are produced between the work piece and the wire terminal. The dielectric liquid is ceaselessly encouraged into the machining zone with required weight. The material is getting expelled by a progression of discrete sparkles occurring at the zone to be machined through electro-warm system. Test set up of the wire electrical release machine is appeared in Figure 1.

Amid machining process little gap kept up between the work and wire material. The machined particles were flushed away by the persistent stream of the dielectric liquid. The wire is held by a stick direct at the upper and lower parts of the work piece. The work example measure utilized as a part of this examination is $95 \times 80$ x $8 \mathrm{~mm}$ rectangular plate. Diffused coated wire of 0.25 $\mathrm{mm}$ diameter was utilized as a part of this investigation. Deionized water was utilized as dielectric liquid at room temperature. In the wake of machining, the examples were cleaned with acid after machining. The surface roughness was measured by Mitutoyo surface roughness tester. 


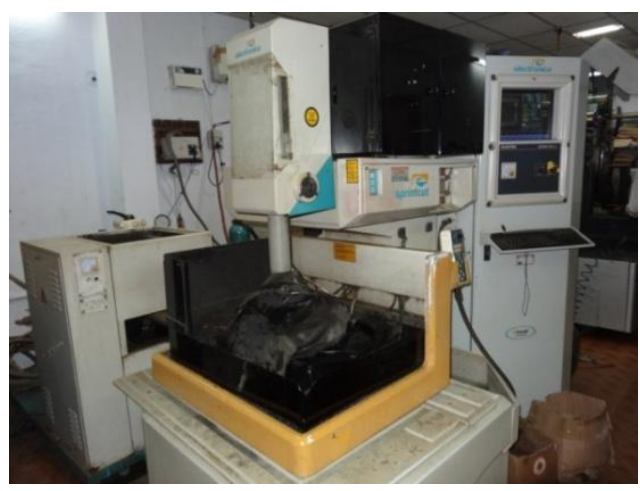

Fig. 1WEDM experimental set up (Electronica Sprint cut)

\section{Results and discussion}

Proper selection of machining parameters is an important step in the WEDM process, which leads to better machining performance. Whereas improperly selected parameters may cause serious problems like shortcircuiting of wire, wire breakage, and deterioration in work piece surface quality, thereby imposing certain limitations on the production schedule and also reducing productivity.

\subsection{Taguchi's analysis}

$\mathrm{S} \backslash \mathrm{N}$ ratio is used to measure the sensitivity of the response which to be investigated at controlled manner. The signal represents attractive effect for the response and noise represents the unwanted effect for the responses. Higher the best (HB) is selected to cutting speed. The $\mathrm{S} / \mathrm{N}$ ratio expression for cutting speed is as follows

Smaller the better

$$
\left(\frac{S}{N}\right) S B=-10 \log \left[\frac{1}{n} \sum_{i=1}^{n} \frac{1}{y^{2}}\right]
$$

Larger the better

Nominal the better

$$
\left(\frac{S}{N}\right) S B=-10 \log \left[\frac{1}{n} \sum_{i=1}^{n} y^{2}\right]
$$

$$
\left(\frac{S}{N}\right) S B=-10 \log \left[\frac{1}{n s} \sum_{i=1}^{n} y^{2}\right]
$$

$Y_{i}$ is the $i_{\text {th }}$ value of response measured

$\mathrm{N}$ the total number of runs and

$\mathrm{S}$ standard deviation

\subsection{Effect of process parameters on surface roughness}

Table 3 shows the average surface roughness data. The analysis showed the effects of six main process parameters while cutting the hybrid aluminum composite. Based on at $95 \%$ confidence level $(x=0.05)$, pulse on duration and gap voltage were significant effect towards surface roughness whereas pulse off time, current, speed of wire drum and wire tension did not have significant effect. Table 7 shows the pooled ANOVA for the surface roughness. The contribution of each parameter is calculated by ANOVA. The pulse off duration was the most significant parameter, which contributed maximum of $33.50 \%$ to the surface roughness. The contribution from other parameters were gap voltage $24.50 \%$. The average $\mathrm{S} / \mathrm{N}$ ratios and average mean values for surface roughness of each parameter are shown in Table 5 and 6 . The performance of each parameter at different levels from the $\mathrm{S} / \mathrm{N}$ ratio analysis the best levels for minimum surface roughness are A1,B3,C1,D2, E1 and F3. The main effect plot for S/N ratio, mean are shown in Figs 3 and 4.

\subsection{Effect of pulse on time on surface roughness}

The effect of pulse on time on the surface roughness was observed from fig.3. Surface roughness, which increases due to increase in pulse on duration increases. The pulse on time is the most significant influencing parameter on surface roughness. High temperature is observed at high intensity discharge energy when the spark strikes the surface. Due to this effect part of specimen to melt and evaporated. Due this effect, a large quantity of material melts and removed. These Results are in line with some of the researchers $[12,24]$.

\subsection{Effect of pulse off time on surface roughness}

The impact of pulse off duration on the surface roughness is shown in figure 3.Increased pulse off time duration reduces surface roughness. This is due to less number of discharges occur for a specific period of time. Thus, small quantity of metal melting takes place for larger pulse off time. This produces lower surface roughness. The results from this investigation are in agreement with other researchers.[12, 25].

\subsection{Effect of pulse current on surface roughness}

Figure 3 indicates the effect of pulse current on the surface roughness. Pulse current is not a significant process parameter affecting the surface roughness. The surface roughness increases as the pulse current increases. Discharge energy becomes intense with an increase in the pulse current, due to this poor surface finish achieved. Hence, to obtain lower surface roughness, the pulse current should be kept low or minimum. These results are in agreement with other researchers $[12,25]$.

\subsection{Effect of gapset voltage on surface roughness}

Figure 3 demonstrates the impact of gap voltage on the surface roughness. Surface roughness decreases with increase in gapset voltage. The influence of gapset 
voltage on surface roughness is significant parameter. Hence, to obtain good surface finish, the gapset voltage should be kept high. These outcomes are in concurrence with different analysts [25].

\subsection{Estimation of optimum performance characteristic}

The optimum value of surface roughness was predicted at the selected level of parameters. The process parameter and their optimum levels are selected from the response graphs as $\mathrm{A}_{1} \mathrm{~B}_{3} \mathrm{C}_{1} \mathrm{D}_{3} \mathrm{E}_{1}$ andF $\mathrm{F}_{3}$, that is pulse on time (level 1), pulse off time (level 3 ), peak current (level 1 ), gapset voltage (level 3), wire speed (level 1) and wire tension (level 3$)$.

$\mu_{\mathrm{SR}}=\mathrm{SR}+\left(\mathrm{A}_{1}-\mathrm{SR}\right)+\left(\mathrm{B}_{3}-\mathrm{SR}\right)+\left(\mathrm{C}_{1}-\mathrm{SR}\right)+\left(\mathrm{D}_{1}-\mathrm{SR}\right)+$ $\left(\mathrm{E}_{1}-\mathrm{SR}\right)+\left(\mathrm{F}_{3}-\mathrm{SR}\right)$

where $\mathrm{SR}$ is the overall mean surface roughness $(2.73$ $\mu \mathrm{m})$. Optimum value of surface roughness was predicted as $1.285 \mu \mathrm{m}$ using Minitab version18statistical software.

Table 2. Taguchi L27 design matrix

\begin{tabular}{|c|c|c|c|c|c|c|}
\hline \multirow{2}{*}{$\begin{array}{l}\text { Exp. } \\
\text { run }\end{array}$} & \multicolumn{6}{|c|}{ Control factors and levels } \\
\hline & A & B & C & D & $\mathbf{E}$ & $\mathbf{F}$ \\
\hline 1 & 1 & 1 & 1 & 1 & 1 & 1 \\
\hline 2 & 1 & 1 & 1 & 1 & 2 & 2 \\
\hline 3 & 1 & 1 & 1 & 1 & 3 & 3 \\
\hline 4 & 1 & 2 & 2 & 2 & 1 & 1 \\
\hline 5 & 1 & 2 & 2 & 2 & 2 & 2 \\
\hline 6 & 1 & 2 & 2 & 2 & 3 & 3 \\
\hline 7 & 1 & 3 & 3 & 3 & 1 & 1 \\
\hline 8 & 1 & 3 & 3 & 3 & 2 & 2 \\
\hline 9 & 1 & 3 & 3 & 3 & 3 & 3 \\
\hline 10 & 2 & 1 & 2 & 3 & 1 & 2 \\
\hline 11 & 2 & 1 & 2 & 3 & 2 & 3 \\
\hline 12 & 2 & 1 & 2 & 3 & 3 & 1 \\
\hline 13 & 2 & 2 & 3 & 1 & 1 & 2 \\
\hline 14 & 2 & 2 & 3 & 1 & 2 & 3 \\
\hline 15 & 2 & 2 & 3 & 1 & 3 & 1 \\
\hline 16 & 2 & 3 & 1 & 2 & 1 & 2 \\
\hline 17 & 2 & 3 & 1 & 2 & 2 & 3 \\
\hline 18 & 2 & 3 & 1 & 2 & 3 & 1 \\
\hline 19 & 3 & 1 & 3 & 2 & 1 & 3 \\
\hline 20 & 3 & 1 & 3 & 2 & 2 & 1 \\
\hline 21 & 3 & 1 & 3 & 2 & 3 & 2 \\
\hline 22 & 3 & 2 & 1 & 3 & 1 & 3 \\
\hline 23 & 3 & 2 & 1 & 3 & 2 & 1 \\
\hline 24 & 3 & 2 & 1 & 3 & 3 & 2 \\
\hline 25 & 3 & 3 & 2 & 1 & 1 & 3 \\
\hline 26 & 3 & 3 & 2 & 1 & 2 & 1 \\
\hline 27 & 3 & 3 & 2 & 1 & 3 & 2 \\
\hline
\end{tabular}

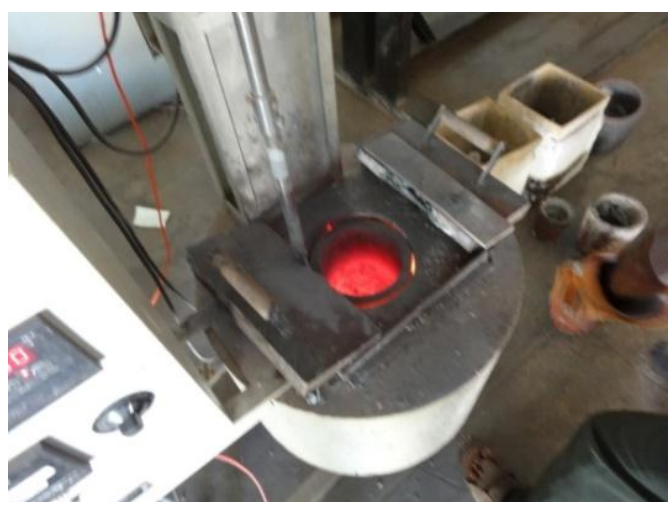

Fig. 1 Stir casting setup

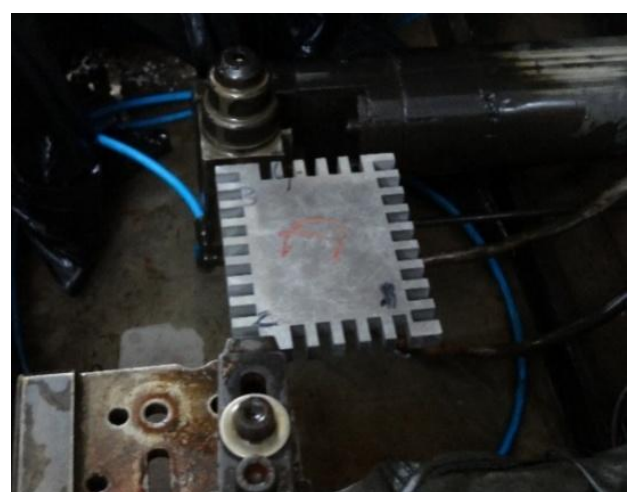

Fig. 2 Machined work piece

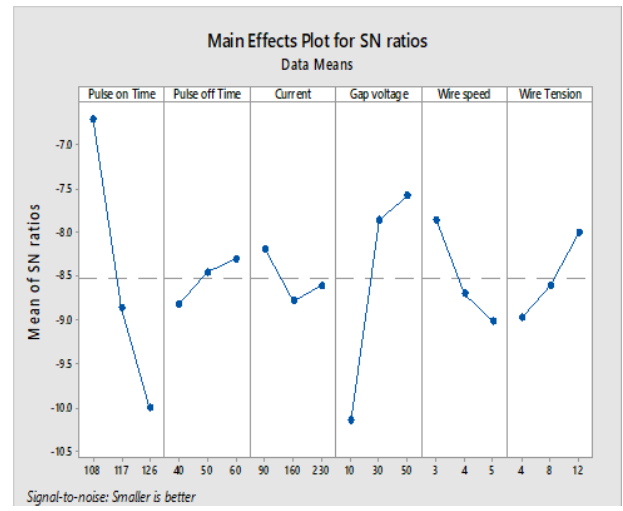

Fig. 3 SR main effect plot for $\mathrm{S} / \mathrm{N}$ ratio

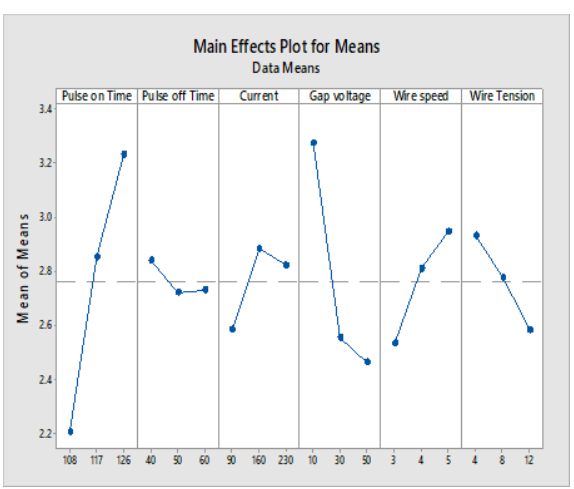

Fig. 4 SR main effect plot for means 
Table 3. Surface roughness and $\mathrm{S} / \mathrm{N}$ ratio

\begin{tabular}{|c|c|c|c|c|c|c|c|c|}
\hline Ex.No. & $\begin{array}{c}\text { Pulse on } \\
\text { Time }\end{array}$ & $\begin{array}{c}\text { Pulse off } \\
\text { Time }\end{array}$ & $\begin{array}{c}\text { Peak } \\
\text { Current }\end{array}$ & $\begin{array}{l}\text { Gap set } \\
\text { voltage }\end{array}$ & $\begin{array}{l}\text { Wire } \\
\text { speed }\end{array}$ & $\begin{array}{c}\text { Wire } \\
\text { Tension }\end{array}$ & $\begin{array}{c}\text { Surface } \\
\text { roughness } \\
(\mu \mathrm{m})\end{array}$ & $\begin{array}{c}\mathrm{S} / \mathrm{N} \\
\text { ratio of } \\
\mathrm{SR}\end{array}$ \\
\hline 1 & 108 & 40 & 90 & 10 & 3 & 4 & 2.42 & -7.6763 \\
\hline 2 & 108 & 40 & 90 & 10 & 4 & 8 & 2.68 & -9.7992 \\
\hline 3 & 108 & 40 & 90 & 10 & 5 & 12 & 2.34 & -7.3843 \\
\hline 4 & 108 & 50 & 160 & 30 & 3 & 4 & 2.14 & -6.6083 \\
\hline 5 & 108 & 50 & 160 & 30 & 4 & 8 & 1.64 & -4.2969 \\
\hline 6 & 108 & 50 & 160 & 30 & 5 & 12 & 2.45 & -7.7833 \\
\hline 7 & 108 & 60 & 230 & 50 & 3 & 4 & 1.77 & -4.9595 \\
\hline 8 & 108 & 60 & 230 & 50 & 4 & 8 & 1.78 & -7.4582 \\
\hline 9 & 108 & 60 & 230 & 50 & 5 & 12 & 1.87 & -4.4543 \\
\hline 10 & 117 & 40 & 160 & 50 & 3 & 8 & 2.06 & -6.2773 \\
\hline 11 & 117 & 40 & 160 & 50 & 4 & 12 & 2.36 & -7.4582 \\
\hline 12 & 117 & 40 & 160 & 50 & 5 & 4 & 2.83 & -11.664 \\
\hline 13 & 117 & 50 & 230 & 10 & 3 & 8 & 2.77 & -8.8496 \\
\hline 14 & 117 & 50 & 230 & 10 & 4 & 12 & 3.39 & -10.604 \\
\hline 15 & 117 & 50 & 230 & 10 & 5 & 4 & 3.98 & -11.9977 \\
\hline 16 & 117 & 60 & 90 & 30 & 3 & 8 & 2.56 & -9.2779 \\
\hline 17 & 117 & 60 & 90 & 30 & 4 & 12 & 2.31 & -7.2722 \\
\hline 18 & 117 & 60 & 90 & 30 & 5 & 4 & 2.45 & -6.3613 \\
\hline 19 & 126 & 40 & 230 & 30 & 3 & 12 & 2.97 & -6.5267 \\
\hline 20 & 126 & 40 & 230 & 30 & 4 & 4 & 3.81 & -11.6185 \\
\hline 21 & 126 & 40 & 230 & 30 & 5 & 8 & 3.54 & -10.9801 \\
\hline 22 & 126 & 50 & 90 & 50 & 3 & 12 & 2.78 & -8.8809 \\
\hline 23 & 126 & 50 & 90 & 50 & 4 & 4 & 2.65 & -8.4649 \\
\hline 24 & 126 & 50 & 90 & 50 & 5 & 8 & 2.7 & -8.6273 \\
\hline 25 & 126 & 60 & 160 & 10 & 3 & 12 & 3.68 & -11.6866 \\
\hline 26 & 126 & 60 & 160 & 10 & 4 & 4 & 3.7 & -11.364 \\
\hline 27 & 126 & 60 & 160 & 10 & 5 & 8 & 3.94 & -11.9099 \\
\hline
\end{tabular}

Table 4. Response table for $\mathrm{S} / \mathrm{N}$ ratio

\begin{tabular}{|c|c|c|c|c|c|c|}
\hline Level & $\begin{array}{c}\text { Pulse on } \\
\text { time }\end{array}$ & $\begin{array}{c}\text { Pulse off } \\
\text { time }\end{array}$ & $\begin{array}{c}\text { Peak } \\
\text { current }\end{array}$ & $\begin{array}{c}\text { gapset } \\
\text { Voltage }\end{array}$ & Wire speed & $\begin{array}{c}\text { Wire } \\
\text { tension }\end{array}$ \\
\hline 1 & -6.713 & -8.821 & -8.194 & -10.141 & -7.86 & -8.968 \\
\hline 2 & -8.862 & -8.457 & -8.783 & -7.858 & -8.704 & -8.608 \\
\hline 3 & -10.007 & -8.305 & -8.605 & -7.583 & -9.018 & -8.006 \\
\hline Delta & 3.293 & 0.516 & 0.589 & 2.559 & 1.158 & 0.963 \\
\hline Rank & 1 & 6 & 5 & 2 & 3 & 4 \\
\hline
\end{tabular}


Table 5. Response table for mean

\begin{tabular}{|c|c|c|c|c|c|c|}
\hline Level & $\begin{array}{c}\text { Pulse on } \\
\text { time }\end{array}$ & $\begin{array}{c}\text { Pulse off } \\
\text { time }\end{array}$ & Peak current & $\begin{array}{c}\text { gapset } \\
\text { Voltage }\end{array}$ & Wire speed & Wire tension \\
\hline 1 & 2.209 & 2.841 & 2.587 & 3.274 & 2.534 & 2.931 \\
\hline 2 & 2.854 & 2.722 & 2.884 & 2.556 & 2.812 & 2.779 \\
\hline 3 & 3.231 & 2.731 & 2.823 & 2.464 & 2.948 & 2.584 \\
\hline Delta & 1.022 & 0.119 & 0.298 & 0.81 & 0.413 & 0.347 \\
\hline Rank & 1 & 6 & 5 & 2 & 3 & 4 \\
\hline
\end{tabular}

Table 6. ANOVA table for surface roughness

\begin{tabular}{|l|c|c|c|c|c|c|}
\hline \multicolumn{1}{|c|}{ Source } & DF & Adj SS & Adj MS & F-Value & P-Value & $\begin{array}{c}\% \\
\text { contribution }\end{array}$ \\
\hline Pulse on time & 2 & 4.8107 & 2.40534 & 8.04 & 0.005 & 33.42 \\
\hline $\begin{array}{l}\text { Pulse off } \\
\text { Time }\end{array}$ & 2 & 0.0789 & 0.03947 & 0.13 & 0.877 & 0.5 \\
\hline Peak current & 2 & 0.4453 & 0.22263 & 0.74 & 0.493 & 3 \\
\hline gapset voltage & 2 & 3.5436 & 1.7718 & 5.92 & 0.014 & 24.56 \\
\hline Wire speed & 2 & 0.7991 & 0.39957 & 1.34 & 0.295 & 5.55 \\
\hline Wire Tension & 2 & 0.5435 & 0.27174 & 0.91 & 0.426 & 3.77 \\
\hline Error & 14 & 4.189 & 0.29921 & & & 29 \\
\hline Total & 26 & 14.4101 & & & & \\
\hline
\end{tabular}

$\mu_{\mathrm{SR}}=\mathrm{SR}+\left(\mathrm{A}_{1}-\mathrm{SR}\right)+\left(\mathrm{B}_{3}-\mathrm{SR}\right)+\left(\mathrm{C}_{1}-\mathrm{SR}\right)+\left(\mathrm{D}_{1}-\mathrm{SR}\right)+\left(\mathrm{E}_{1}-\right.$ $\mathrm{SR})+\left(\mathrm{F}_{3}-\mathrm{SR}\right)$

where SR is the overall mean surface roughness $(2.73$ $\mu \mathrm{m})$. Optimum value of surface roughness was predicted as $1.285 \mu \mathrm{m}$ using Minitab version 18 statistical software.

\subsection{Mathematical model for surface roughness}

Surfaces roughness is an important performance measure that dictates the manufacturing quality of the WEDMed components. If the surface finish of the machined part is the decisive factor due to its application requirements, then the work material must be machined with low cutting speed. Based on the proposed quadratic process order, the regression equation defining the relation between surface roughness and process parameters in terms of coded factors is given by

Surface roughness $=-3.75+0.0568$ pulse on Time 0.0055 pulse off time +0.00169 current -0.02025 Gap voltage +0.207 Wire speed -0.0433 Wire tension (1)
The model was successfully developed such that the changes in the input parameter reflects the output. Mathematical modeling of the response variables (surface roughness) was made using a Taguchi's design and the experimental results were compared with the predicted values of the response variables to decide about the closeness of the predictions to the experimental values. Figure 5 shows the comparison of the experimental and the predicted value of surface roughness.

\section{Surface Roughness}

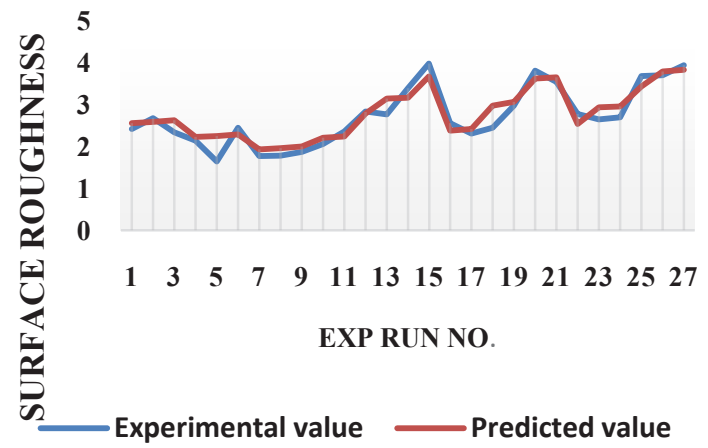

Fig 5. Comparison of the experimental and the predicted data 


\section{Conclusions}

Hybrid MMC of $15 \mathrm{wt} \% \mathrm{SiC}(10 \%)$ and graphite $(5 \%)$ particulates in Al6061 alloy was prepared using stir casting process. The cast hybrid composite was machined on wire electrical discharge machine. The estimation of optimum machining parameters to maximize cutting speed was investigated using Taguchi's technique was studied. The conclusions drawn from this study are as follows:

- The process parameters pulse on time gap voltage are significant on surface roughness. Peak current, pulse off time, wire speed and wire tension did not have significant effect on surface roughness.

- The pulse on time was the most significant parameter contributing to the surface roughness ( $33.42 \%)$, followed by Gapset voltage (24.56\%) and wire speed $(5.51 \%)$. The contribution of pulse off time, wire tension were less than $1 \%$ effect.

- The optimum value of process parameters for the predicted optimum value of surface roughness (1.285) is pulse on time 106 units (Level 1), pulse off time 60 units (Level 3), peak current 90 units (Level 2), gap set voltage 50 units (Level 3 ), wire speed3 units (Level 1) and wire tension 12 units (Level 3). The optimum results are adopted in validation study and the results based on WEDM process responses can be effectively improved.

- The model was successfully developed using regression equation that the changes in the input parameter reflects the output. The variation between experimental value and predicted value was minimum. A good agreement between experimental and prediction results (using Regression model) was perceived for surface roughness. However, the prediction accuracy is limited to the studied range of the machining parameters. The percentage accuracy of both the prediction tools can be further improved by testing and conducting the experiments at a varying range of input parameters.

\section{References}

1. C. Tatar, N. Ozdemir, Physica B Condens Matter. 405, 896-899 (2010).

2. A. Manna, H.S. Bains, P.B. Mahapatra, J Compos Mater. 45(19), 2003-2010 (2011).

3. N. Tosun, C. Cogun, G. Tosun, J Mater Process Technol. 152, 316-322 (2004).

4. N.O. Hung, N.L. Loh, Z.M. Xu, J Mater Process Technol. 58, 114-120 (1996).

5. M.K. Surappa, Sadhana, 28, 319-334 (2003).

6. 6. R. Snoeys, F. Staelens, W. Dekeyser, Ann. CIRP, 35/2, 467-480 (1986).
7. T.W. Clyne, P.J. Whithers, An introduction to metal matrix composites (Cambridge University Press, London, 1992).

8. D.B. Miracle, Compos. Sci. Technol. 65, 25262540 (2005).

9. M. Singh, B.K. Prasad, D.P. Mondal, A.K. Jha, Tribology International. 34, 557-567 (2001).

10. W. Pedersen, M. Ramulu, J Mater Process Technol. 172, 417-423 (2006).

11. Shyam Lal, Sudhir Kumar, ZA Khan, AN Siddiquee, Proceedings of the Institution of Mechanical Engineers, Part-B: Journal of Engineering Manufacture, 8, 1-9, 2014.

12. 12.Shyam Lal, Sudhir Kumar, ZA Khan, AN Siddiquee, J. Braz. Soc. Mech. Sci. \& Eng. 36, 335-346 (2014).

13. Bikash Chaoudhuri, Ruma Sen, Subrata Kumar Ghosh, Subhash Chandra Saha Proceedings of the Institution of Mechanical Engineers, Part-B: Journal of Engineering Manufacture. 8, 1-15, (2015).

14. Adeel Ikram1, Nadeem Ahmad Mufti, Muhammad Qaiser Saleem, Ahmed Raza Khan, Journal of Mechanical Science and Technology, 2133-2141 (2013).

15. S.S. Mahapatra, A. Patnaik, Int J Adv Manuf Technol. 34, 911-925 (2007).

16. G. Ugrasen, H.V. Ravindra, Naveen Prakash, R. Keshavamurthy Procedia Materials Science, 6, 1752 - 1760 (2014).

17. D. Sudhakara, G. Prasanthi, Procedia Engineering. 97, 1565-1576 (2014).

18. K. Kanlayasiri, S. Boonmung, Journal of Materials Processing Technology, 192, 459-464 (2007).

19. BH. Yan, HC. Tsai, FY. Huang, LC. Lee, Int J Mach Tools Manuf. 45, 251-259 (2005).

20. T.P.D. Rajan, P.M. Pillai, B.C. Pai, K.G. Satyanarayana, P.K. Rohatgi, Journal of Composites and Technology. 67, 15-16 (2007).

21. S. Singh, S. Maheshwari, PC. Pandey, J Mater Process Technol. 149, 272-277 (2004).

22. R. Ramakrishnan, L. Karunamoorthy, J Mater Process Technol. 207, 343-349 (2008).

23. A. Muniappan, C. Thiagarajan, S. Somasundaram, IJMME-IJENS. 16(5), 95-103 (2017).

24. A. Muniappan, C. Thiagarajan, S.Somasundaram, ARPN Journal of Engineering and Applied Sciences. 12(2), 382-388 (2017),

25. R. Ramakrishnan, L. Karunamoorthy, Int J Mater Prod Technol. 35, 199-215 (2009).

26. S. Sarkar, S. Mitra, B. Bhattacharyya, J Mater Process Technol, 159, 286-294 (2005). 